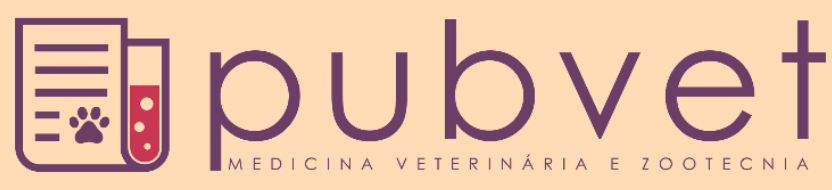

https://doi.org/10.31533/pubvet.v13n12a474.1-3

\title{
Mucocele salivar em canino: relato de caso
}

\author{
Mary'Anne Rodrigues de Souza ${ }^{1^{*} \bullet}$, Ana Angélica Costa Rezende ${ }^{2}$, Ana Karoline Goes de \\ Jesus $^{30}$, Leonardo Ribeiro Santos ${ }^{4}{ }^{\circ}$ \\ ${ }^{1}$ Professora da Faculdade Pio Décimo, Departamento de Medicina Veterinária. Aracaju - SE Brasil. \\ ${ }^{2}$ Médica veterinária ${ }^{3}$ Graduanda em Medicina Veterinária, Faculdade Pio Décimo. Aracaju - SE Brasil. \\ ${ }^{4}$ Graduando em Medicina Veterinária, Faculdade Pio Décimo. Aracaju - SE Brasil. \\ *Autor para correspondência,E-mail: maryanne_vet@hotmail.com
}

Resumo. A Mucocele salivar é compreendida como a coleção de muco advindo de trauma no ducto salivar excretor ou pela sua obstrução. Trata-se de uma patologia comum em cães machos, em geral com idade adulta. Os pacientes apresentam-se com sinais clínicos que compreendem o aumento de volume oral. O diagnóstico pode ser feito pela condição clínica. O tratamento da mucocele envolve a extirpação da glândula salivar acometida e a drenagem de seu conteúdo. O presente trabalho teve como objetivo principal descrever a ocorrência da mucocele em um cão macho, da raça Poodle, com 13 anos de idade, que apresentou como queixa principal um aumento na região submandibular que estava dificultando a alimentação e descanso do animal, o tratamento cirúrgico consistiu na remoção cirúrgica da mucocele salivar. Concluiu-se que o tratamento escolhido foi eficaz para solucionar o surgimento da mucocele no cão.

Palavras chave: Cães, glândulas salivares, sialocele, tratamento

\section{Salivary mucocele in a dog: case report}

Abstract. The salivary Mucocele is understood as the collection or mucus resulting from trauma to the excretory or salivary duct obstruction. It is a common pathology in male dogs, generally with adulthood. Patients present with clinical signs that comprise the oral with consequent volume increase facial contour changes. The diagnosis can be made by clinical condition. The treatment of mucocele involves the removal of the affected salivary gland and draining its contents. The present work had as main objective to analyze the occurrence of Mucocele in a male dog, Poodle breed, with 13 years of age, which in 2014 presented as main complaint an increase in bilateral submaxillary region that was making it difficult to feed and rest of the animal, if surgical treatment consisted in surgical removal of salivary mucocele. It was concluded that the treatment was effective when you troubleshoot parsed the rise of Mucocele in dog observed.

Keywords: Dogs, salivary gland, sialocele, treatment

\section{Mucocele salivar en canino: reporte de caso}

Resumen. La Mucocele salivar es comprendida como la colección de moco que viene de trauma en el conducto salivar excretor o por su obstrucción. Se trata de una patología común en perros machos, en general con edad adulta. Los pacientes se presentan con signos clínicos que comprenden el aumento de volumen oral. El diagnóstico puede ser hecho por la condición clínica. El tratamiento del mucocele implica la extirpación de la glándula salivar acometida y el drenaje de su contenido. El presente trabajo tuvo como objetivo principal describir la ocurrencia del mucocele en un perro macho, de la raza Poodle, con 13 años de edad, que presentó como queja principal un aumento en la región submandibular 
que estaba dificultando la alimentación y descanso del animal, el tratamiento quirúrgico consistió en la remoción quirúrgica del mucocele salivar. Se concluyó que el tratamiento analizado fue eficaz para solucionar el surgimiento del mucocele en el perro.

Palabras clave: Glándulas salivares, perro, sialocele, tratamiento

\section{Introdução}

Compreende por mucocele salivar a coleção ou muco advindo de trauma no ducto salivar excretor ou pela sua obstrução (Fossum, 2014). É uma patologia comum em cães machos (Ata-Ali et al., 2010; Pike et al., 2004) em geral com idade adulta.

Esses pacientes apresentam-se com sinais clínicos que compreendem o aumento de volume facial com consequente contorno submandibular alterado, hemorragia local, dor ao abrir a boca, passagem das patas na boca, halitose, sialorreia intensa, disfagia, perda dentária, exoftalmia, tosse, dispneia, descarga nasal, rinite crônica, anorexia, perda de peso ou fratura patológica (da mandíbula ou da maxila) por comprometimento ósseo grave (Dias et al., 2013). O diagnóstico pode ser feito pela condição clínica (Dias et al., 2015) e invariavelmente em tratamento cirúrgico, o qual pode ser realizado por meio de diferentes técnicas (Fossum, 2014). O tratamento da mucocele envolve a extirpação da glândula salivar acometida e a drenagem de seu conteúdo (Ata-Ali et al., 2010).

O presente trabalho teve como objetivo apresentar, através de um relato de caso, a ocorrência da Mucocele em um cão macho, da raça Poodle, com 13 anos de idade, que em 2014 que apresentou como queixa principal aumento na região submandibular que estava dificultando a alimentação e descanso do animal. Foi acompanhado o diagnóstico, o tratamento clínico e seus resultados.

\section{Material e métodos}

Foi atendido na Clínica Veterinária Clinipet, em Aracaju/Sergipe, um cão macho, da raça Poodle, 13 anos de idade e com $10 \mathrm{~kg}$ de peso vivo. A queixa inicial do proprietário estava relacionada ao aumento de volume na região submandibular que estava dificultando a alimentação e descanso do animal.

Durante a anamnese constatou-se que o paciente estava vacinado e vermifugado. Na inspeção física verificou-se aumento de volume na região submaxilar bilateral cuja consistência era macia, não apresentava aderência e era indolor a palpação, na qual se realizou punção na região central, de onde fluiu um líquido viscoso e espumoso o qual foi posto em uma lâmina de vidro e enviado para citologia. Em adição solicitou-se exame radiográfico e exames de sangue.

O sangue foi coletado por venopunção na veia cefálica esquerda e encaminhado para hemograma e bioquímicos (ALT - alamiaminotransferase; FA - fostatase alcalina; ureia e creatinina) os quais não apresentaram nenhuma alteração. Diante de todos os exames, foi sugerida a remoção cirúrgica da mucocele salivar, com a técnica de sialodenectomia.

O animal foi submetido à anestesia inalatória, iniciada pela indução anestésica com Proporfol na dose de $8 \mathrm{ml} / \mathrm{kg}$, manutenção anestésica com Isoflurano a $2 \% \mathrm{~V}$, mantido a oxigênio $100 \%$ e infusão continua de Fentanil na dose de $0,04 \mathrm{mg} / \mathrm{min}$. Previamente à cirurgia realizou-se tricotomia da região submandibular, seguida da antissepsia com solução de Clorexidina $0,5 \%$ e colocação dos panos de campo.

Iniciou-se o procedimento cirúrgico mediante incisão reta na pele, seguida do divulsionamento do subcutâneo, margeando a mucocele e de forma delicada a fim de não provocar sua ruptura, entretanto a ruptura ocorreu. Durante a cirurgia foi observado que havia apenas uma glândula e não duas como foi suspeito no exame físico.

Ainda no pós-operatório o animal apresentou edema na região submandibular, sendo este resolvido em 24 horas, neste mesmo período de tempo o animal voltou a se alimentar e beber água normalmente, sendo assim, dado alta cirúrgica e recomendado a remoção dos pontos após 10 dias, situação que ocorreu sem intercorrências.

\section{Resultados e discussão}

O perfil do paciente descrito neste relato está de acordo com o referenciado na literatura (Visnieski et al., 2013), a saber, a mucocele geralmente é relatada em cães de pequeno e médio porte, neste caso 
um Poodle. Tratando-se de um animal de 13 anos, quando a maioria tem em geral uma média de idade de 9 anos (Kahn et al., 2005). Além de ser macho (Dias et al., 2015).

Contrapondo o descrito por (Dias et al., 2015), o animal não apresentava hemorragia local, dor ao abrir a boca, não passava as patas na boca, não apresentava sialorreia intensa, disfagia, perda dentária, exoftalmia, tosse, descarga nasal, rinite crônica, anorexia, ou fratura patológica (da mandíbula ou maxila) por comprometimento ósseo grave. Contudo, o proprietário relatou dispneia, halitose e perda de peso. Halitose que pode estar associada ao depósito de placa bacteriana. O diagnóstico da mucocele é fácil e definitivo. Contudo, requer do clínico conhecimento prévio da patologia (Ata-Ali et al., 2010; Quinn \& Cook, 2009). Pode-se além da anamnese estabelecer o diagnóstico com uso de exames complementares como CAAF (Dias et al., 2015), e serem realizadas radiografias (Kahn et al., 2005).

O resultado da citologia revelou um infiltrado inflamatório misto composto por linfócitos, neutrófilos e macrófagos com citoplasma abundante e de aspecto espumoso. Havendo também formação de células gigantes com mais de um núcleo, e com presença de manchas ao fundo da lâmina caracterizando a presença de material proteináceo, mais uma vez coincidindo com descrição da literatura (Dias et al., 2015).

A técnica cirúrgica adotada obedeceu à indicação de vários autores (Andrade, 2011; Dias et al., 2015; Fossum, 2014; Pignone et al., 2009; Piozzi, 2005; Stuani et al., 2010). Contudo, apesar da destreza cirúrgica a ruptura da mucocele ocorreu, dificultou o procedimento, entretanto nos empenhamos para localizar o "desemboque do ducto" o qual foi ligado. Como previsto por Fossum (2014) o animal apresentou edema na região submandibular após 24 horas do procedimento. Doravante, o curso pósoperatório correu dentro do previsto, com para remoção dos pontos10 dias e clinicamente apresentavase sem nenhuma alteração. Demonstrando assim a aplicabilidade e exequibilidade da técnica para a resolução da mucocele salivar.

\section{Referências bibliográficas}

Andrade, E. C. (2011). Ressecção bilateral de glândulas salivares no tratamento da sialocele cervical em cão. Relato de caso. Revista CFMV, 5444-48.

Ata-Ali, J., Carrillo, C., Bonet, C., Balaguer, J., Peñarrocha, M. \& Peñarrocha, M. (2010). Oral mucocele: review of the literature. Journal of Clinic Exp Dent, 2(1):18-21.

Dias, F., Dias, L., Pereira, L., Cabrini, T. \& Rocha, J. (2013). Neoplasias orais nos animais de companhia-Revisão de literatura. Revista Científica Eletrônica de Medicina Veterinária, 20(1):1-9.

Fossum, T. W. (2014). Cirurgia de pequenos animais (4 ed. Vol. 1). São Paulo: Elsevier Brasil.

Kahn, C. M., Line, S. \& Aiello, S. (2005). The merck veterinary manual. Merck \& Co. USA: Whitehouse Station.

Pignone, V. N., Faraco, S., Albuquerque, P. B., Recla, G., Gianotti, G. \& Contesi, N. I., E. A. (2009). Sialólito no ducto da glândula mandibular em cão. Acta Veterinariae, 37(3):277-280.

Pike, F. S., Berg, J., King, N. W., Penninck, D. G. \& Webster, C. R. (2004). Gallbladder mucocele in dogs: 30 cases (2000-2002). Journal of the American Veterinary Medical Association, 224(10):1615-1622.

Piozzi, R. (2005). Mucocele - Relato de caso clínico. Revista Internacional de Estomatologia, 2(4):9-13.

Quinn, R. \& Cook, A. K. (2009). update on gallbladder mucoceles in dogs. Veterinary Medicine, 103(4):169-175.

Stuani, A. S., Stuani, A. S., Silva, F. W. G. P., Stuani, M. B. S., Valério, R. A. \& Queiroz, A. M. (2010). Mucoceles: lesões freqüentes na cavidade bucal de crianças. Pediatria, 32(4):288-292.

Visnieski, C., Barella, F., Nardino, D. M. \& Festugatto, R. (2013). Obstrução respiratória causada por mucocele salivar faríngea em um cão. Revista de Ciências Agroveterinárias, 1313-14.

Recebido: 11 de julho, 2019.

Aprovado: 1 de agosto, 2019.

Publicado: 24 de janeiro, 2020.

Licenciamento: Este artigo é publicado na modalidade Acesso Aberto sob a licença Creative Commons Atribuição 4.0 (CC-BY 4.0), a qual permite uso irrestrito, distribuição, reprodução em qualquer meio, desde que o autor e a fonte sejam devidamente creditados. 